University of Nebraska - Lincoln

DigitalCommons@University of Nebraska - Lincoln

1998

\title{
The effect of background cuing on prey detection
}

\author{
Henry Kono \\ University of Massachusetts \\ Pamela J. Reid \\ University of Nebraska - Lincoln \\ Alan Kamil \\ University of Nebraska - Lincoln, akamil1@unl.edu
}

Follow this and additional works at: https://digitalcommons.unl.edu/bioscibehavior

Part of the Behavior and Ethology Commons

Kono, Henry; Reid, Pamela J.; and Kamil, Alan, "The effect of background cuing on prey detection" (1998). Papers in Behavior and Biological Sciences. 72.

https://digitalcommons.unl.edu/bioscibehavior/72

This Article is brought to you for free and open access by the Papers in the Biological Sciences at DigitalCommons@University of Nebraska - Lincoln. It has been accepted for inclusion in Papers in Behavior and Biological Sciences by an authorized administrator of DigitalCommons@University of Nebraska - Lincoln. 


\title{
The effect of background cuing on prey detection
}

\author{
Henry Kono \\ Department of Zoology, University of Massachusetts \\ Pamela J. Reid \& Alan C. Kamil \\ School of Biological Sciences, University of Nebraska \\ Corresponding author - A. C. Kamil, School of Biological Sciences, University of Nebraska-Lincoln, \\ Lincoln, NE 68588-0I I8, USA; email akamil@unl.edu \\ Current address for P.J. Reid: School of Veterinary Sciences, University of Guelph, Guelph, Ontario NIG 2WI, Canada
}

\begin{abstract}
Studies of prey detection have typically focused on how search image affects the capture of cryptic items. This study also considers how background vegetation influences cryptic prey detection. Blue jays, Cyanocitta cristata, searched digitized images for two Catocala moths: $C$. ilia, which is cryptic on oak, and C. relicta, which is cryptic on birch. Some images contained moths while others did not. The ability of blue jays to detect prey during repeated presentations of one prey type within a session was compared with their performance during randomly alternating presentations of both prey types within a session to examine search-image formation under two background conditions (informative and ambiguous). In the informative background condition, both trees in the image were of the same species and therefore, the background was a reliable indicator of which prey type might be present. In the ambiguous background condition, there was one tree of each species in the image and either prey type could be present. The results indicate that: (I) a search-image effect was observed only for the more cryptic prey type and only when the background was informative; (2) as accuracy on prey images (those with moths) increased, response latency remained unchanged; (3) performance on nonprey images (those without moths) was primarily determined by the difficulty of searching the background and not by the prey type in the accompanying prey images; and (4) search-image effects disappeared with extended practice. These results suggest that the ability to detect prey is influenced by background and that the presence of either multiple backgrounds or multiple prey types interferes with search-image formation.
\end{abstract}

Cryptic coloration and patterning are common defenses against predation. Prey that blend in with the background can be extremely difficult to detect. Despite the masquerade, however, predators can "break" a cryptic defense. Exactly how a predator detects cryptic prey has been debated since Tinbergen (1960) first suggested that birds form "specific search images" for the cryptic insects they hunt. Tinbergen suggested that chance encounters with a novel prey type resulted in a perceptual change that allowed the bird to detect items of that same species or type more easily.

While the concept of search images is intuitively attractive, methodologically sound demonstrations of the phenomenon are scarce. In a study by Pietrewicz \& Kamil (1979), highly trained blue jays, Cyanocitta cristata, searched projected photographic images for two species of Catocala moth, each cryptic against an appropriate tree background. During repeated presentations of one prey type (a run), the birds progressively improved their ability to detect both the presence and the absence of the moth. During mixed presentations of both moth species (a nonrun), however, the birds showed no improvement across trials and, overall, detectability was worse. Pietrewicz \& Kamil concluded that exclusive experience with one prey type resulted in the formation of a search image for that type, thereby improving detectability. In contrast, concurrent experience with both prey types prevented the formation of a search image for either type and detectability remained unchanged.

In the natural environment there are many sources of information available to the predator regarding what prey type is likely to be present. An obvious and very salient source is the microhabitat being searched. For instance, $\mathrm{Ca}$ tocala moths, including those used by Pietrewicz \& Kamil (1979), are cryptically colored and patterned to blend in with tree bark. In any one region, sympatric species tend to be cryptic on different species of trees and the moths preferentially rest on the appropriate trees (Sargent 1981). A predator could learn that C. relicta moths, for example, rest on birch and then search for moths resembling C. relicta when searching a birch microhabitat. 
While most recent laboratory studies of prey detection have used prey types designed to be cryptic against a common background (Blough 1991, 1992; Bond \& Riley 1991; Reid \& Shettleworth 1992; Langley et al. 1995; Plaisted \& Mackintosh 1995), Pietrewicz \& Kamil's (1979) set-up was unique in that the two moth types were presented to the birds against the species-appropriate tree backgrounds, $C$. relicta on birch and C. retecta on oak. In addition to improving their ability to detect the two prey types, the birds could also have learned to focus search on the prey type appropriate for the particular tree presented in the photograph. In fact, it is possible that the search-image effect these researchers recorded was influenced by the birds' ability to associate each background with the corresponding species of moth and to direct search accordingly. It could be that the difference Pietrewicz \& Kamil observed between performance during run and nonrun sessions was actually diminished by the background-moth association, which should have benefited the birds in both types of sessions.

The idea that a predator might search for a particular prey type as a result of reliably associated environmental cues is not novel. Blough (1989) proposed an interpretation of search images based on an associative-priming process. Priming is said to occur when one stimulus, the prime, affects the processing of a second stimulus (for theoretical accounts of priming, see McKoon \& Ratcliff 1992; Schacter 1992). For example, recognition of a word such as "chair" is facilitated if preceded by a related word such as "table" (Whittlesea \& Jacoby 1990).

Blough (1989) trained pigeons to detect two visual targets. Each trial was preceded by a visual cue. The cue was either informative (it accurately predicted which target would be presented), incorrect (it predicted the wrong target), or ambiguous (it was not reliably associated with either target). Detection of the target was fastest during trials preceded by an informative cue, intermediate during trials preceded by an ambiguous cue, and slowest during trials preceded by an incorrect cue. Taken together, the findings of Blough (1989) and Pietrewicz \& Kamil (1979) suggest the operation of both a search-image process and an associative-cuing process.

Our research addresses the possibility that both processes operate to enhance cryptic prey detection. We propose that some process resulting from repeated exposures to the same prey type establishes a search image for the type, while associative priming cues (in this case, tree backgrounds) identify the target likely to be present. Moreover, we suggest that a cue reliably associated with a certain prey type might also function to activate an appropriate search image and further enhance detection.

We examined both the effect of repeated presentations of a specific prey type and the effect of background information on subsequent prey detection in blue jays. We trained blue jays to search digitized images for two Catocala moth species, C. ilia which is cryptic on oak, and C. relicta which is cryptic on birch. We classified images as either informative or ambiguous. Informative images contained two trees in the background, both oak or both birch, which were consistent with the type of prey that might be pres- ent. Ambiguous images contained two trees, one oak and one birch, and consequently, did not convey which prey type might be present. For each background, performance during repeated presentations of only one prey type (runs) was contrasted with performance during mixed presentations of both prey types (nonruns) to assess short-term improvements due to search-image formation. This design allowed us to separate the influence of background information from the search-image effect.

For both background conditions, we expected higher accuracy and quicker response times during run sessions than during nonrun sessions because run sessions provided the opportunity to establish a search image for the prey type. Furthermore, we anticipated the jays would perform better with an informative background than with an ambiguous background because background information should have cued the jays to search for a specific prey type. Finally, we envisioned that if the jays established a search image for the correct type and were able to restrict their search to the appropriate tree, optimum performance would occur during run sessions with the ambiguous background. Even though both tree backgrounds were present, if the jay came to expect only one prey type during the session it would be advantageous for the jay to restrict search to the corresponding tree while ignoring the other.

\section{METHODS}

\section{Subjects}

We trained six blue jays for the experiment. All had previous experience in operant tasks. The jays, which were obtained in the Amherst, Massachusetts area and hand-reared in the laboratory, were $4-5$ years old at the start of the experiment. Throughout the study, the jays were maintained at $80 \%+0.5 \mathrm{~g}$ of their ad libitum weights with daily feedings of turkey starter and myna pellets. The jays were housed in individual cages, with water available, at a constant room temperature of $27^{\circ} \mathrm{C}$ and on a $14: 10 \mathrm{~h}$ light:dark cycle. Two jays were eliminated from the study for health reasons and their data discarded.

\section{Apparatus}

We tested the jays in an operant chamber, $50.8 \times 36.8$ $\times 45.7 \mathrm{~cm}$, with opaque walls (Figure 1). We mounted an overhead feeder light and a food cup on the back wall. We fitted the hole $(27.9 \times 21.6 \mathrm{~cm})$ in the front wall with a Carroll Touch 12" infrared touch screen (Model 8001-4117-01) that reported Cartesian coordinates to a computer each time a peck was directed at the screen. We attached a sheet of clear Plexiglas, $27.3 \times 21.4 \mathrm{~cm}$, to the back of the touch screen by springs. The Plexiglas protected the monitor from being damaged by the bird's pecks while the spring system protected the bird's bill. We placed a house light, which remained lit throughout a session, above the touch screen. We affixed a wooden perch to the chamber wall $10.5 \mathrm{~cm}$ away from the touch screen and $11.5 \mathrm{~cm}$ above the chamber floor. 


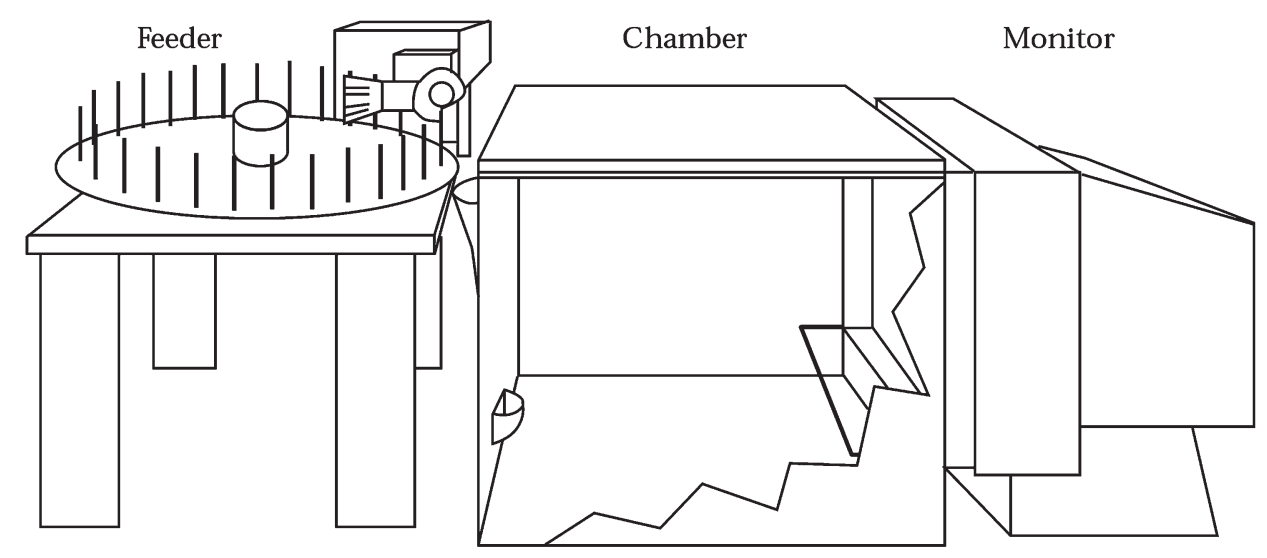

Figure I. Diagram of the experimental set-up.

We also placed a NEC Multisync 14" color monitor (Model JC-1401P3A), used to display the digitized images, $2.5 \mathrm{~cm}$ behind the touch screen. We removed the front bezel of the monitor and replaced it with a steel frame to minimize parallax resulting from the distance between the monitor and the touch screen.

We rewarded the jays with mealworm, Tenebrio molitor, larvae halves dispensed into the food cup from a Davis UF-100 feeder situated outside the back wall of the chamber. We played white noise through a speaker attached to a side wall of the chamber to mask outside sounds. All stimulus presentations and data collection were controlled by an Epson Equity III+ computer. The computer and operant chamber were situated in a small, darkened room.

\section{Stimulus Images}

We created digitized images with a Panasonic WV-3260$8 \mathrm{AF}$ video camera equipped with a $10.5-84 \mathrm{~mm}$ zoom lens, and an AT\&T TARGA 16 graphics board. We used a subject-to-camera distance of $3.3 \mathrm{~m}$. We used C. relicta and C. ilia moths in the images, with forewings covering the hindwings. We created the initial set of training images by pinning a moth onto a plain styrofoam background, with C. relicta against a yellow background and C. ilia against a grey background. The moth measured $1 \times 0.7 \mathrm{~cm}$ and appeared in one of nine possible locations on the monitor.

We produced a second set of training images to facilitate recognition of the moths against the natural tree backgrounds, oak (Quercus rubra) and birch (Betula papyrifera) logs. We pinned the moths in locations that appeared conspicuous to the human eye. There were three background conditions: two oak logs placed side-by-side in the image, two birch logs placed side-by-side, or one oak log and one birch log placed side-by-side. In the latter condition, we alternated placement of the logs to avoid the possibility of confounding a tree preference with a side preference. To create the set of prey images (images with moths), we placed a moth on the species-appropriate tree background in one of 32 locations (to produce a set of 128 prey images, 32 per moth/background type). We created the set of nonprey images (images without moths) by pre- paring one image of each background type with no moth (to produce a set of four nonprey images: pure oak, pure birch, and two of one oak and one birch with tree position counterbalanced).

The set of test images was identical to the previous training images except that we placed the moth in locations where it appeared cryptic to the human eye. The logs and moths used for these images differed from those used in the training images. We used two specimens of each moth type and one side of each log to create the set of test images. Each image as it appeared on the monitor was $12.5 \times$ $12.5 \mathrm{~cm}$ in size.

\section{Design}

We classified each session according to prey type (C. ilia or C. relicta), background condition (informative or ambiguous), and sequence (runs or nonruns). The informative background contained two trees of the same species; the ambiguous background contained one tree of each species. During run sequences, only one prey type was presented in all prey trials (and the corresponding background in nonprey trials). During nonrun sequences, each prey type appeared in prey trials equally often. Thus, there were: (1) informative run sessions of $C$. relicta; (2) informative run sessions of C. ilia; (3) ambiguous run sessions of C. relicta; (4) ambiguous run sessions of $C$. ilia; (5) informative nonrun sessions of both prey types (with equal numbers of oak and birch nonprey images); and (6) ambiguous nonrun sessions of both prey types (all images contained one oak and one birch). Session condition was randomly chosen each day, with the constraint that each jay experienced one of each condition in every set of six sessions.

\section{Pretraining}

We acquainted the blue jays with the experimental chamber using standard habituation/magazine training procedures. Once the birds reliably associated the feeder light and the sound of the feeder with the delivery of food, we trained them to peck at a red circle, $2.5 \mathrm{~cm}$ in diameter (the start key), presented on the monitor. Upon completion 

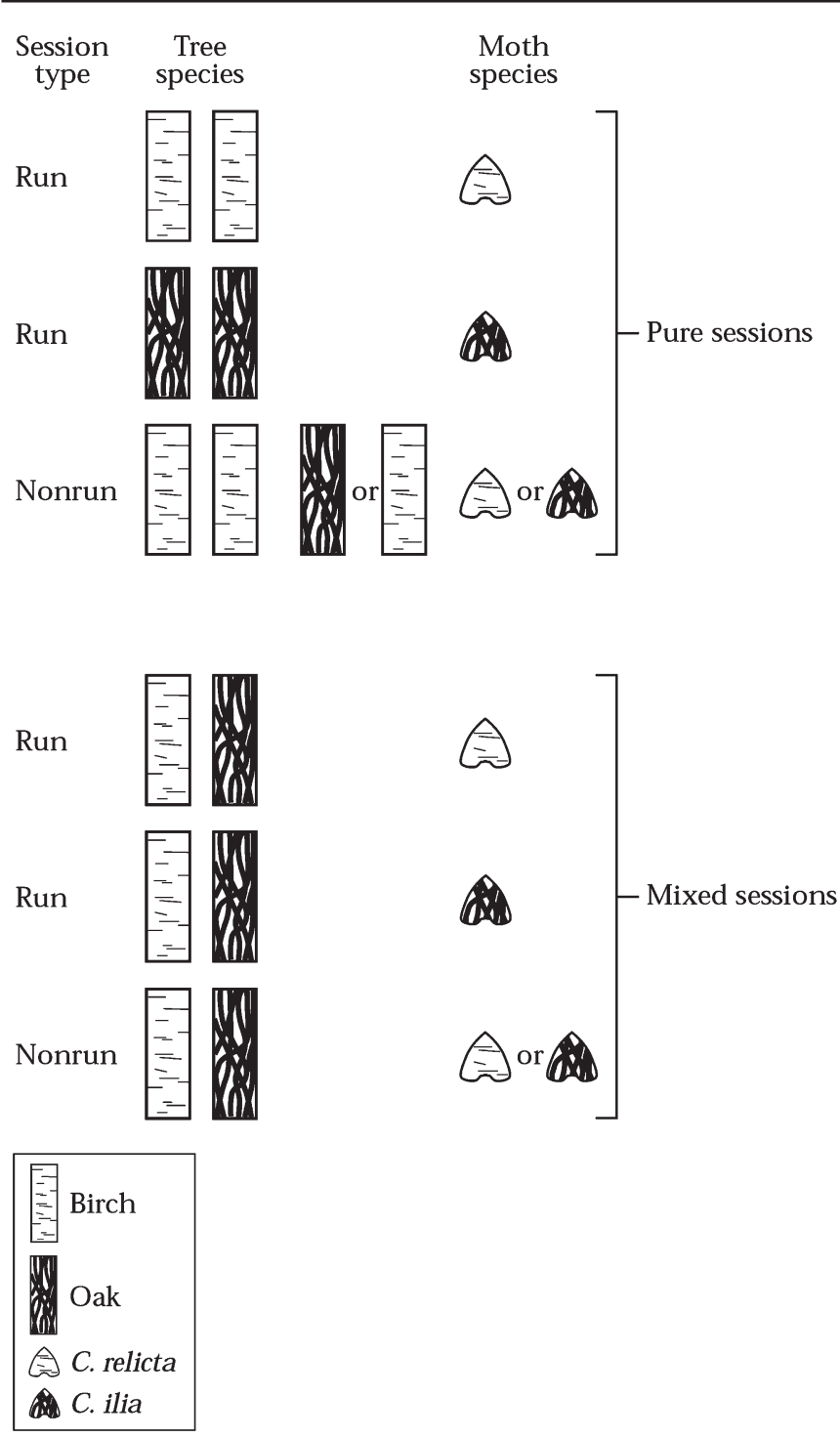

Figure 2. The six session types presented to blue jays. In informative sessions, trees of the same species were presented and in ambiguous sessions, trees of two different species were presented. Run sessions involved repeated presentations of the same prey type and nonrun sessions involved random alternations of two prey types.

of this stage of training, we introduced the first set of training images, in which the moth appeared against a styrofoam background. At the start of a trial, the start key appeared. After a peck to the start key, the key disappeared and an image appeared on the right of the screen. A peck to the moth was followed by the delivery of food and an intertrial interval before the next trial began. Initially, we scored any pecks directed within a large area $(10 \mathrm{~cm}$ in $\mathrm{di}-$ ameter from the centre of the moth) on the touch screen surrounding the moth as "correct." We gradually reduced the area to approximately $4 \mathrm{~cm}$ in diameter from the centre of the moth.

During the next stage of training, we introduced the set of images containing tree backgrounds and conspicuously placed moths. In addition, we presented a green circle (the leave key) next to the image (in the same location as the start key) and trained the jays to peck this key in response to nonprey images. Initially, we used a selection of the 10 most conspicuous prey images with each background type. Gradually the pool was increased to include the entire set of 128 images. Jays received two 32-trial sessions daily with an equal number of prey and nonprey images in each session. The jays completed training when they responded with approximately $80 \%$ accuracy to both prey and nonprey images over the course of 6 days.

\section{Experimental Procedure}

During the testing stage, we introduced the final set of images containing cryptic moths. Each jay received two daily sessions of 32 trials each. Sessions within a day were separated by a minimum of $1.5 \mathrm{~h}$. Each trial began when the start key appeared on the left of the monitor screen. A peck to the key caused it to turn green after a 1-s delay (becoming the leave key) and at the same time, an image appeared to the right of the key. During half of the trials, the image contained prey, and during the other half, the image contained no prey, with the constraint that no more than three nonprey images could occur in a row. The jay could respond by pecking at the image or by pecking at the leave key. If the jay did not respond within 360 s, we ended the trial with a 15-s intertrial interval and an additional 45-s delay penalty before beginning the next trial (these trials were classified as aborted). For each trial, we recorded the location and the time of every peck.

If the image contained a prey, the correct response was to peck at the moth five times. After one peck to the moth, the leave key was darkened. Although the first correct peck determined the outcome of the trial, we required five pecks because the additional effort has been shown to facilitate learning (Roberts 1972; Sacks et al. 1972). Following five correct pecks, a reward was dispensed. Reward was followed by a 15-s intertrial interval. If the jay pecked the leave key on the first peck or made 10 pecks that were not directed at the moth, we ended the trial without reward, and with a 15-s intertrial interval and an additional 45-s delay penalty.

If the image did not contain a prey, the correct response was to peck the leave key. We did not reward the bird with food for indicating the absence of a moth. We initiated the next trial after a 15-s intertrial interval. The jay could make as many as nine pecks at a nonprey image without consequence, but after 10 pecks, we ended the trial without reward, and with a 15-s intertrial interval and an additional 45-s delay penalty.

\section{Dependent Measures}

We analyzed two dependent measures: proportion correct and response latency. For prey trials, the proportion correct was the number of trials during which the jay pecked at the moth the required five times divided by the total number of prey trials the jay completed. For nonprey trials, the proportion correct was the number of trials during which the jay correctly indicated the absence of a moth 
Table I. Mean $( \pm S E)$ proportion of correct responses by blue jays and mean $( \pm S E)$ latencies to respond to prey images of each prey type

\begin{tabular}{cllll}
\hline & Background & C. ilia run & C. relicta run & Nonrun \\
\hline $\begin{array}{c}\text { Proportion correct } \\
\text { Initial sessions }\end{array}$ & Informative & $0.90 I \pm 0.045$ & $0.547 \pm 0.064$ & $0.723 \pm 0.07$ I \\
& Ambiguous & $0.876 \pm 0.033$ & $0.519 \pm 0.049$ & $0.679 \pm 0.053$ \\
Final sessions & Informative & $0.894 \pm 0.049$ & $0.8 I I \pm 0.05$ I & $0.83 I \pm 0.052$ \\
& Ambiguous & $0.919 \pm 0.036$ & $0.730 \pm 0.046$ & $0.815 \pm 0.047$ \\
Response latency & & & \\
Initial sessions & Informative & $3.5 I \pm 0.334$ & $8.52 \pm 0.626$ & $6.07 \pm 0.628$ \\
Final sessions & Ambiguous & $4.24 \pm 0.489$ & $7.60 \pm 0.777$ & $6.11 \pm 0.64 I$ \\
& Informative & $3.82 \pm 0.512$ & $6.30 \pm 0.555$ & $4.93 \pm 0.355$ \\
& Ambiguous & $4.57 \pm 0.585$ & $6.18 \pm 0.309$ & $5.11 \pm 0.564$ \\
\hline
\end{tabular}

Table 2. Mean $( \pm \mathrm{SE})$ proportion of correct responses by blue jays and mean $( \pm \mathrm{SE})$ latencies to reject nonprey images within each session condition

\begin{tabular}{cllll}
\hline & Background & C. ilia run & C. relicta run & Nonrun \\
\hline $\begin{array}{c}\text { Proportion correct } \\
\text { Initial sessions }\end{array}$ & Informative & $0.976 \pm 0.008$ & $0.742 \pm 0.03 \mathrm{I}$ & $0.866 \pm 0.025$ \\
& Ambiguous & $0.881 \pm 0.025$ & $0.820 \pm 0.030$ & $0.866 \pm 0.026$ \\
Final sessions & Informative & $0.992 \pm 0.008$ & $0.925 \pm 0.013$ & $0.978 \pm 0.008$ \\
& Ambiguous & $0.960 \pm 0.015$ & $0.970 \pm 0.01 \mathrm{I}$ & $0.983 \pm 0.006$ \\
Response latency & & & \\
Initial sessions & Informative & $17.50 \pm 1.45$ & $27.44 \pm 1.63$ & $21.08 \pm \mathrm{I} .7 \mathrm{I}$ \\
\multirow{2}{*}{ Final sessions } & Ambiguous & $22.84 \pm 2.38$ & $22.60 \pm 1.77$ & $22.01 \pm 2.1 \mathrm{I}$ \\
& Informative & $13.69 \pm 1.35$ & $23.46 \pm 1.86$ & $19.50 \pm 1.23$ \\
& Ambiguous & $18.25 \pm 1.4 \mathrm{I}$ & $20.68 \pm 1.67$ & $19.13 \pm 1.36$ \\
\hline
\end{tabular}

by pecking the leave key divided by the total number of nonprey trials the jay completed. We defined response latency as the time elapsed from the beginning of a trial to the jay's first peck at the moth (prey trials) or the leave key (nonprey trials). For a small number of trials, we recorded response times greater than $300 \mathrm{~s}$. To avoid skewing the data, we truncated all latencies greater than $60 \mathrm{~s}$ to $60 \mathrm{~s}$.

\section{RESULTS}

Each jay completed 144 sessions, 24 of each of the six conditions. We discarded one session for each of three birds because of experimenter error. We analyzed prey and nonprey trials separately and excluded data from aborted trials.

Although the birds were trained extensively prior to testing, their ability to perform the search task improved during initial sessions. Therefore, we divided the experiment into the initial 72 sessions and the final 72 sessions (12 sessions per condition) and analyzed these data separately. We subjected each data set to an analysis of variance with three factors: (1) prey type (runs of C. ilia, runs of C. relicta, and nonruns of both species); (2) background condition (informative and ambiguous); and (3) preceding moth detections (trials). We arcsine transformed the data for the proportion of correct responses for the analyses. Where appropriate, we investigated significant effects with pairwise $t$ tests. A probability level of 0.05 was used for all statistical tests.

\section{Prey Trials}

\section{Performance between sessions}

Despite our intention that the two prey types appear equally cryptic, C. ilia was obviously more conspicuous than $C$. relicta. The jays detected significantly more $C$. ilia than $C$. relicta during both the initial $\left(F_{2,6}=23.72, P<0.01\right)$ and final $\left(F_{2,6}=15.61, P<0.01\right)$ sessions (Table 1$)$. The jays' ability to detect $C$. relicta moths improved from the initial to the final sessions, although search accuracy remained lower for C. relicta than for C. ilia, which were almost always detected from the start of the experiment. They were also able to detect $C$. ilia more quickly than $C$. relicta during both the initial $\left(F_{2,6}=45.66, P<0.01\right)$ and final $\left(F_{2,6}=272.56\right.$, $P<0.01)$ sessions. During the initial sessions, the jays took, on average, $8 \mathrm{~s}$ to detect $C$. relicta and only $4 \mathrm{~s}$ to detect $C$. ilia. During the final sessions, the time needed for the jays to detect $C$. relicta moths decreased to $6 \mathrm{~s}$, even though the moths were detected with greater accuracy than during the initial sessions.

During the final sessions, the jays' ability to detect a prey type was affected by the background, $F_{2,6}=13.20, P$ $<0.05$. During runs of $C$. relicta, more moths were detected against the informative birch background than against the ambiguous background. During runs of C. ilia and during nonruns, prey detectability was unaffected by background condition. Response latencies for both prey types in runs and nonruns were unaffected by background condition. 

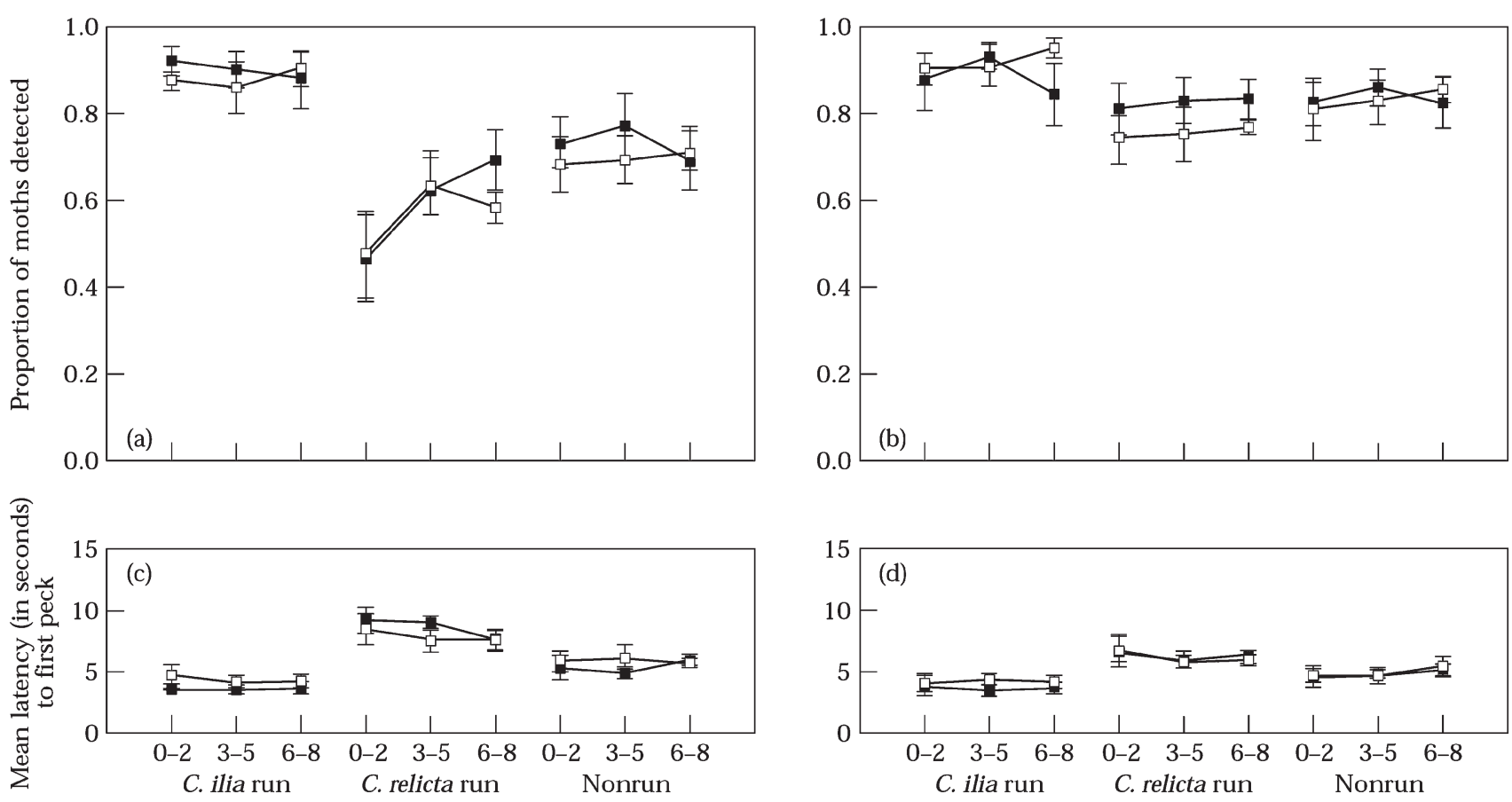

Number of moths previously detected

Figure 3. Mean $( \pm S E)$ proportion of moths detected (a: initial sessions; b: final sessions) and the mean ( \pm SE) latency in seconds to the first peck at a moth (c: initial session; d: final sessions) during run sequences of $C$. ilia, $C$. relicta, and nonrun sequences of both species, as a function of the number of moths previously detected in the session and the type of background in the image. $\mathbf{\square}:$ Informative background; $\square:$ ambiguous background.

\section{Performance within sessions}

To examine within-session performance, we blocked trials by the number of prey detections that had preceded the trial. The fewest prey detected by any of the birds in any one session was nine, so we grouped trials into three blocks according to the number of preceding moth detections up to a maximum of eight. Subsequent trials in the session were excluded. The first block of each session included prey trials preceded by as many as two moth detections, the second block included prey trials preceded by as many as five moth detections, and the third block included prey trials preceded by as many as eight moth detections. Thus, trial blocks differed in the amount of recent previous experience the birds had detecting the prey type or types available during the session.

During the initial sessions (Figure 3a), there was a significant interaction of prey type, background, and the number of previous detections within the session $\left(F_{4,12}=4.18\right.$, $P<0.05)$. The jays' accuracy improved as they gained experience detecting moths during runs of $C$. relicta, but only when the moths were presented on an informative background of two birch trees (significant linear component: $F_{1,3}$ $=40.43, P<0.05)$. When the images contained an ambiguous background of one birch and one oak tree, accuracy improved from the first to the second block, but decreased from the second to the third block of trials (significant quadratic component: $\left.F_{1,3}=63.24, P<0.05\right)$. During runs of $C$. ilia and during nonruns, the number of previous detections did not affect prey detectability.
There were no within-session changes in accuracy for either prey type during the final sessions of the experiment (Figure $3 \mathrm{~b}$ ). There were also no within-session changes in response latency for either prey type throughout the experiment (Figure 3c, d).

\section{Nonprey Trials}

\section{Performance between sessions}

Nonprey images were categorized according to the prey-type session during which they were presented (i.e. C. ilia runs, C. relicta runs, and nonruns). During the initial sessions, nonprey images were rejected more accurately $\left(F_{2,3}=50.30, P<0.01\right)$ and more quickly $\left(F_{2,3}=14.79, P<\right.$ $0.05)$ during $C$. ilia runs than during $C$. relicta runs. Accuracy and response latency measures for nonprey trials during nonruns was intermediate and did not differ from performance during C. ilia or C. relicta runs (Table 2).

During the final sessions, the jays rejected nonprey images accurately, regardless of the prey type presented in prey trials. However, nonprey images were still rejected more quickly during $C$. relicta runs than during $C$. ilia runs, with intermediate response latencies during nonruns $\left(F_{2,3}\right.$ $=44.06, P<0.01)$. The jays' ability to reject nonprey images and the speed at which they were rejected was affected by an interaction between the type of background in the images and session condition, during both the initial (accuracy: $F_{2,6}=23.36, P<0.01$; response latency: $F_{2,6}=13.55, P<$ 0.05 ) and the final (accuracy: $F_{2,6}=28.44, P<0.01$; response 

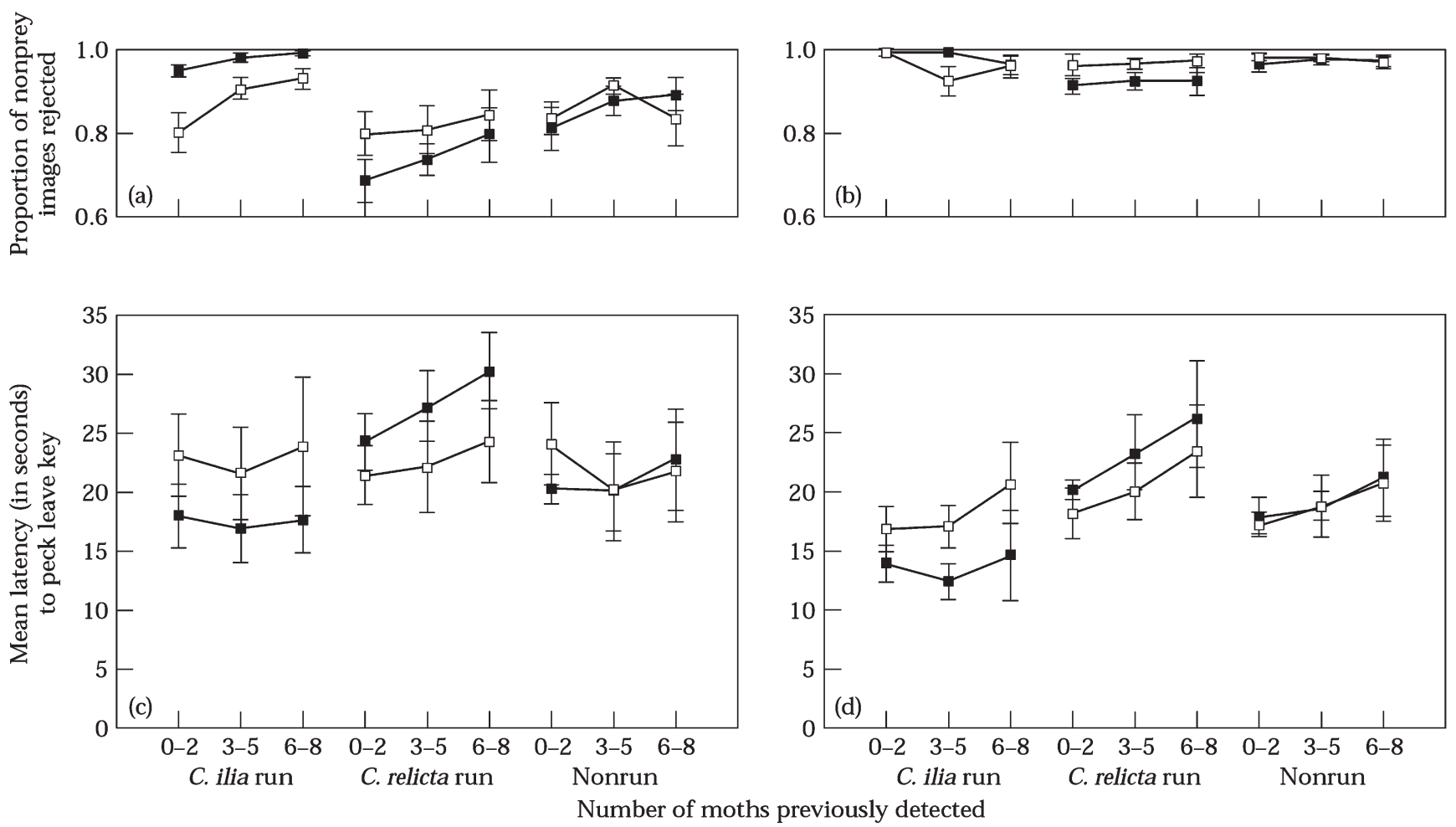

Figure 4. Mean $( \pm S E)$ proportion of nonprey images rejected (a: initial sessions; b: final sessions) and the mean ( \pm SE) latency to peck the leave key (c: initial session; d: final sessions) during run sequences of $C$. ilia, $C$. relicta, and nonrun sequences of both species, as a function of the number of moths previously detected in the session and the type of background in the image. $\mathbf{a}$ : Informative background; $\square$ : ambiguous background.

latency: $F_{2,6}=42.19, P<0.01$ ) sessions. During runs of $C$. ilia, nonprey images with a background of two oak trees were rejected more accurately and more quickly than nonprey images with the ambiguous background of both oak and birch. In contrast, during runs of C. relicta, nonprey images with the ambiguous background were rejected more accurately and more quickly than nonprey images with a background of two birch trees. During nonruns, accuracy and response latency for nonprey images was unaffected by background condition.

\section{Performance within sessions}

Like the breakdown for prey trials, the first block of trials included nonprey trials preceded by as many as two moth detections, the second block included nonprey trials preceded by as many as five moth detections, and the third block included nonprey trials preceded by as many as eight moth detections. During the initial sessions, the proportion of nonprey images rejected increased as the jays gained experience detecting moths, $\left(F_{2,6}=15.86, P<0.01\right.$; Figure $\left.4 \mathrm{a}\right)$. Subsequent two-way ANOVAs were performed separately on the proportion of correct data from C. ilia runs, C. relicta runs, and nonruns. During both $C$. ilia and C. relicta runs, the jays' ability to reject nonprey images improved from the first to the third block of moth detections $\left(F_{2,3}=50.36, P\right.$ $<0.01$ for C. ilia and $F_{2,3}=7.54, P<0.05$ for C. relicta). During nonruns, there was no change in the jays' ability to reject nonprey images within a session. During the final ses- sions of the experiment, the jays were extremely accurate at rejecting nonprey images and were unaffected by the number of moth detections made previously (Figure 4c).

During the initial sessions, there was an interaction of background condition and previous moth detections on the latency to reject nonprey images $\left(F_{2,6}=7.37, P<0.05\right.$; Figure $4 b)$. Although the increase was slight, it took the jays more time to reject nonprey images as the number of previous moth detections increased, particularly with an informative background. During the final sessions, there was a significant interaction of session type and previous moth detections on the latency to reject nonprey images $\left(F_{4,12}=3.57\right.$, $P<0.05$; Figure $4 \mathrm{~d}$ ). Particularly during $C$. relicta runs, the jays took increasingly more time to reject nonprey images as the number of previous moth detections increased within the session. There was also a slight increase in response latency across trials during C. ilia runs and during nonruns.

\section{DISCUSSION}

The purpose of this study was to examine the influence of search-image formation and associative cuing on the detection of cryptic prey. We manipulated the order in which different types of prey were encountered (search image) and whether the trees shown in the images signaled which prey type might be available (associative cue). The results demonstrate effects of both search image and cuing. However, the results were not straightforward. 
Search-image effects were tested either by repeatedly presenting images of only one prey type (a run) or by presenting a mix of images of one or the other prey type (a nonrun) within a session. The search-image hypothesis predicts that the jays should progressively improve their ability to detect the prey type during runs more than during nonruns. The sequence manipulation produced results that were consistent with search image, but only during the initial sessions of the experiment and only when C. relicta was shown against an informative background. In this condition, the proportion correct for prey images increased across trials within runs but not within nonruns.

Why should search-image effects be restricted to a single set of circumstances? Part of the explanation for these findings relates to the level of crypticity of the prey types. With regard to accuracy of prey detection, many researchers have reported enhanced detection only for prey types that are difficult to perceive against the background (e.g. Dawkins 1971; Reid \& Shettleworth 1992). In the case of $C$. ilia, performance was near perfect from the onset of testing for both background conditions and probably provided no room for improvement. In addition, the detection of C. relicta increased from the initial sessions to the final sessions of the experiment. With practice, the birds appeared to learn to detect $C$. relicta with greater proficiency, in effect reducing the crypticity of $C$. relicta.

The results suggest that the search-image process is very closely tied to the difficulty level of the prey-detection task. The moths may have become easier for the jays to detect with continued experience with the same set of images (128 prey and 4 nonprey), thereby eliminating the usefulness of a search image. Plaisted \& Mackintosh (1995) examined the performance of pigeons searching for cryptic prey items and, similarly, only found a run effect early in their experiment. However, the blue jays in Pietrewicz \& Kamil's (1979) study searched the same set of 40 slides (20 prey and 20 nonprey) for 1080 trials (27 sessions of 40 trials each) and yet large run effects were observed. The run effect in our experiment disappeared after only 384 trials. Further examination of the effect of practice on the run effect seems warranted.

Another interesting issue arises from performance on nonprey images. During the initial sessions of the experiment, identifying the absence of a prey item also improved during runs. As with prey images, the run effect on nonprey images only occurred under certain conditions. The proportion correct for nonprey images increased across blocks of trials during runs of both C. relicta and C. ilia, but the improvement was greater during runs of $C$. relicta. Furthermore, during runs of $C$. relicta, the jays' ability to reject nonprey images improved most across trials when the background was informative, while during runs of C. ilia, the greatest improvement occurred when the background was ambiguous.

Why does background have these effects on enhanced identification of nonprey images? The run effect was dependent upon the background rather than upon the prey type experienced during prey trials (which are necessarily confounded). Oak trees appear to be the easiest to search while birch trees are more difficult, and images containing one birch and one oak are intermediate. Thus, the magnitude of the run effect on the accuracy of nonprey identification was correlated with the difficulty of the backgrounds being searched. With nonprey trials, practice also served to eliminate the run effect during the final sessions of the experiment. Accuracy for nonprey images, irrespective of background condition, was near perfect during the final sessions.

However, task difficulty alone cannot explain all of the effects. In particular, the nature of the background shown in the images interacted with the run effect. This is most clearly shown by the unexpected finding of a run effect on C. relicta prey images only for the informative and not for the ambiguous background condition. This is consistent with the results of Pietrewicz \& Kamil (1979), who also found enhanced prey detection during runs of one prey type using images of forest scenes with one tree in focus. In the current experiment, the simple presence of an oak tree in the ambiguous background images appears to have interfered with a search image for $C$. relicta. Perhaps the oak tree cued the bird to search for C. ilia, thus disrupting the activation of a search image for C. relicta. Because the majority of studies on prey detection have used prey types cryptic against a common background, there was no previous evidence to suggest that the introduction of a second background would cause search-image interference similar to that of a second prey type.

One interesting feature of the background manipulation was that nonprey images containing the ambiguous background were identical regardless of the type of prey presented in the prey images. If the jays adapted their search strategy to fit the current session type (i.e. searching only for $C$. relicta on birch during C. relicta runs and searching only for C. ilia on oak during C. ilia runs), then their performance on an ambiguous background with nonprey images should have varied as a function of the accompanying prey images presented during the session. However, the data show that the jays' performance on ambiguous backgrounds with nonprey images was very similar during runs and nonruns. This implies that the background is the primary influence affecting the jays' ability to recognize the absence of prey.

Similarly, we had hypothesized that once the birds learned to restrict search to a single prey type during run sessions, superior performance might be observed for the ambiguous background condition because only one tree would need to searched. But response latencies during runs were no lower for the ambiguous background than for the informative background condition. Although it is clear that the informative- versus ambiguous-background manipulation had effects on prey detection, they were not the effects we expected at the outset because the birds apparently still searched both trees.

To a large extent, response-latency data confirm the search-accuracy data, although there were relatively few factors that affected the time required to detect a moth. For example, the jays required more time to detect $C$. re- 
licta than C. ilia and as accuracy on the cryptic C. relicta improved from the initial to the final sessions of the experiment, response latency decreased.

For nonprey trials during $C$. ilia runs, the ambiguous background took longer to search than an informative background of oak trees, but there was no change in response time across trials for either background condition. But some aspects were intriguing. The jays took increasing amounts of time to reject nonprey images as more moths were detected within a session. This effect was most dramatic during runs of $C$. relicta, with both the informative and ambiguous backgrounds. However, response latencies also continued to increase across blocks of detections both during nonruns and during $C$. ilia runs. This is particularly surprising because during the final sessions of the experiment, accuracy was near perfect and therefore the increasing time to reject nonprey images could not result in further increases in accuracy. It also should be noted that this effect of increasing time required to reject nonprey images was greatest in the condition that produced the clearest search-image effects, runs of C. relicta. In essence, the jays took more time as their ability to detect the absence of $C$. relicta against a background of two birch trees increased (as per cent correct increased, so did response latency). This effect persisted into the final sessions of the experiment, when the run effect on search accuracy had disappeared. In addition, the jays did not take any longer to recognize the absence of prey during nonruns, when either type could be present, than during runs, when the bird need only search for one type.

One obvious feature of the latency data is that the birds always took longer to reject a nonprey image than to detect a moth in a prey image. This implies they are using a self-terminating search strategy (Sternberg 1975; Treisman \& Gelade 1980). On prey trials, the bird probably scans the image only until a moth is detected and then makes the decision to respond. On nonprey trials, the bird scans the entire image at least once and possibly numerous times before deciding that a moth is not present. However, it is difficult to understand why the birds took longer to reject nonprey images as the session progressed, even under conditions in which accuracy was not changing.

Finally, it is also interesting that the birds took so much longer to reject a nonprey image than to find a moth. This tendency is consistent with earlier work on prey detection (Pietrewicz 1977; Kamil et al. 1985; Bond \& Riley 1991) and with other foraging studies. For instance, research on patch residence (Kamil et al. 1993) has shown that jays remain much longer in empty food patches than predicted by an optimality analysis, even when prey are completely noncryptic. The fact that the tendency to overstay appears in quite disparate tasks suggests that the underlying cause is not a function of any specific features of the prey-detection problem, but instead may be a product of a motivational damper on performance or may reflect the adoption of an extremely conservative strategy.

In summary, the results of our experiment suggest that short-term changes in a visual predator's ability to detect the presence and absence of prey result from recent experience with the prey. However, the search-image effect we observed was extremely sensitive to the degree of prey crypsis. Our findings also clearly indicate that the background upon which the prey type is normally found is an important component of prey detection. Most surprising, a second tree species within the area to be searched seemed to interfere with search-image formation for a specific prey type in the same manner as do multiple prey types. This implies that once the predator has learned the association between prey type and background, the background itself can serve to cue attention towards the prey type, even in the absence of recent experience with that type. However, in other respects, the birds in our study did not use the information provided by recent experience or the background to search in an efficient manner. Further analysis of how predators use predictive information would seem to be a worthwhile contribution to our understanding of the prey-detection problem.

\section{Acknowledgments}

We thank Pamela Nims for her assistance in collecting the data, and Deborah Olson for comments on an earlier version of this manuscript. Supported by NSF grants BNS8908969 and IBN 9631044.

\section{REFERENCES}

Blough, P. M. 1989. Attentional priming and search images in pigeons. Journal of Experimental Psychology:Animal Behavior Processes, I5, 21 I-223.

Blough, P. M. 199I. Selective attention and search images in pigeons. Journal of Experimental Psychology:Animal Behavior Processes, I 7, 292-298.

Blough, P. M. 1992. Detectability and choice during visual search: joint effects of sequential priming and discriminability. Animal Learning and Behavior, 20, 293-300.

Bond, A. B. \& Riley, D. A. 1991. Searching image in the pigeon: a test of three hypothetical mechanisms. Ethology, 87, 203-224.

Dawkins, M. 197I. Perceptual changes in chicks: another look at the 'search image' concept. Animal Behaviour, 19, 566-574.

Kamil, A. C., Lindstrom, F. \&, Peters, J. 1985. Foraging for cryptic prey by blue jays. I. The effects of travel time. Animal Behaviour, 33, 1068-1079.

Kamil,A. C., Misthal, R., \& Stephens, D.W. 1993. Failure of simple optimal foraging models to predict residence time when patch quality is uncertain. Behavioral Ecology, 4, 350-363.

Langley, C. M., Riley, D. A., Bond, A. B., \& Goel, N. 1995. Visual search for natural grains in pigeons (Columba livia): search images and selective attention. Journal of Experimental Psychology: Animal Behavior Processes, 22, 139-151.

McKoon, G. \& Ratcliff, R. 1992. Spreading activation versus compound cue accounts of priming: mediated priming revisited. Journal of Experimental Psychology: Learning, Memory and Cognition, I 8, II55-II72.

Pietrewicz, A. T. 1977. Search image formation in the blue jay (Cyanocitta cristata). Ph.D. thesis, University of Massachusetts.

Pietrewicz, A. T. \& Kamil, A. C. 1979. Search image formation in the blue jay (Cyanocitta cristata). Science, 204, I332-1 333. 
Plaisted, K. C. \& Mackintosh, N. J. 1995. Visual search for cryptic stimuli in pigeons: implications for the search image and search rate hypotheses. Animal Behaviour, 50, 1219-1 232.

Reid, P. J. \& Shettleworth, S. J. 1992. Detection of cryptic prey: search image or search rate? Journal of Experimental Psychology: Animal Behavior Processes, 18, 273-286.

Roberts, W. A. 1972. Short-term memory in the pigeon: effects of repetition and spacing. Journal of Experimental Psychology Animal Behavior Proceedings, 6, 21 7-237.

Sacks, R. A., Kamil, A. C., \& Mack, R. 1972. The effects of fixedratio sample requirements on matching-to-sample in the pigeon. Psychonomic Science, I 7, 483-488.

Sargent, T. D. 1981. Antipredator adaptations of underwing moths. In: Foraging Behavior: Ethological and Psychological Approaches (Ed. by A. C. Kamil \& T. D. Sargent), pp. 259-284. New York: Garland STPM Press.
Schacter, D. L. 1992. Priming and multiple memory systems: perceptual mechanisms of implicit memory. Journal of Cognitive Neuroscience, 4, 244-256.

Sternberg, S. 1975. Memory scanning: new findings and current controversies. Quarterly Journal of Experimental Psychology, 27, $1-32$.

Tinbergen, L. 1960. The natural control of insects in pinewoods. I. Factors influencing the intensity of predation by song birds. Archives Néerlandaises de Zoologie, I 3, 265-343.

Treisman, A. M. \& Gelade, G. 1980. A feature-integration theory of attention. Cognitive Psychology, I 2, 97-136.

Whittlesea, B.W. \& Jacoby, L. L. 1990. Interaction of priming repetition with visual degradation: is priming a retrieval phenomenon? Journal of Memory and Language, 29, 546-565. 